\title{
RANCANG BANGUN APLIKASI PERSEDIAAN BARANG PADA CV RIDHO KARYA MANDIRI BEKASI
}

\author{
Novendha Hanjas Dwi Nanggara \\ Program Studi Teknik Informatika, Fakultas Teknik dan Ilmu Komputer, \\ Universitas Indraprasta PGRI \\ Jalan Raya Tengah No 80, Kelurahan Gedong, Pasar Rebo, Jakarta Timur \\ novendha.hanjasdn@gmail.com
}

\begin{abstract}
Abstrak
Permasalahan pada CV Ridho Karya Mandiri adalah belum tersedianya aplikasi persediaan barang sehingga belum dapat mengelola data persediaan barang secara efektif dan efisien. Tujuan penelitian ini adalah merancang aplikasi persediaan barang yang sesuai dengan permasalahan kegiatan persediaan barang pada CV Ridho Karya Mandiri agar mempermudah bagian gudang dalam setiap pengelolaan data. Metode yang digunakan pada penelitian ini adalah metode Grounded Research yang merupakan metode penelitian berdasarkan observasi dan wawancara. Aplikasi ini dibuat menggunakan Java Netbeans dan database MySQL. Aplikasi persediaan barang ini dibuat agar dapat meningkatkan efektifitas dan efisiensi waktu dalam proses pendataan stok barang, data pelanggan, data supplier, data barang masuk serta data barang keluar.
\end{abstract}

Kata Kunci: Aplikasi Persediaan Barang, Stok Barang, UML, MySQL, Netbeans

\begin{abstract}
Problems with the CV Ridho Karya Mandiri is not yet available for goods inventory applications so it has not been able to manage inventory data effectively and efficiently. The purpose of this research is to design an application of inventory of goods that is in accordance with the problem of goods inventory activities on the $C V$ Ridho Karya Mandiri to facilitate the warehouse part in every data management. The method used in this study is the Grounded Research method which is a research method based on observation and interview. The application is created using Java Netbeans and MySQL databases. This inventory application is made in order to increase the effectiveness and time efficiency in the process of stocking goods, customer data, supplier data, incoming goods data and exit goods data.
\end{abstract}

Keywords: Inventory Application, Stock of Goods, UML, MySQL, Netbeans

\section{PENDAHULUAN}

CV Ridho Karya Mandiri selalu melakukan pengawasan dan pencatatan terhadap persediaan barang. Selama ini untuk pengolahan data pelanggan, data barang masuk, data barang keluar, data pelanggan serta data stok barang masih dilakukan secara manual oleh bagian gudang ke dalam buku besar. Sehingga menimbulkan kesalahan pada perhitungan barang, pencatatan barang, pembuatan laporan dan pencarian data barang. Untuk mengatasi permasalahan tersebut peneliti melakukan riset agar sistem yang lama dalam usaha tersebut diterapkan menggunakan sistem yang baru atau aplikasi yang ada di komputer dengan software Java Netbeans.

Penggunaan aplikasi untuk mengatasi masalah tersebut memiliki manfaat serta berfungsi untuk pemecahan masalah. Pendataan barang masuk, barang keluar, data pelanggan, data supplier, dan data stok barang yang sebelumnya dilakukan secara manual dapat berubah menjadi aplikasi pengolahan data yg lebih akurat dan efisien dengan sistem yang sudah terkomputerisasi. Dalam pembuatan aplikasi tersebut peneliti memakai software Java Netbeans sebagai pembangun aplikasi dan MySQL sebagai database. Berdasarkan uraian latar belakang tersebut, maka akan dilakukan penelitian tentang "Rancang Bangun Aplikasi Persediaan Barang Berbasis Java Netbeans Pada CV Ridho Karya Mandiri Bekasi”.

Aplikasi adalah software yang dibuat oleh suatu perusahaan komputer untuk mengerjakan tugas tugas tertentu (Asropudin, 2013). Persediaan merupakan jenis aktiva lancar dan jumlahnya cukup besar pada suatu perusahaan (Sartono, 2010). Definisi java menurut Sun Microsystem yaitu nama untuk suatu kumpulan teknologi untuk membuat serta menjalankan software pada komputer atau pada lingkungan jaringan. Java 2 merupakan generasi yang kedua dari platform milik java (Shalahuddin \& Rosa, 2013). Basis data (database) adalah suatu kumpulan data yang terhubung dan disimpan secara bersama pada suatu media serta tanpa saling mengatap atau tidak perlu sebuah 
kerangkapan data, disimpan dengan cara tertentu agar mudah digunakan (Sutanta, 2011). Netbeans merupakan sebuah aplikasi Integrated Development Environment yang menggunakan bahasa pemrograman java yang berjalan diatas swing (Nofriadi, 2015). MySQL adalah database server yang sering digunakan pada pemograman PHP yang digunakan sebagai penyimpan data dalam database serta memanipulasi data - data yang diperlukan (Buana, 2014).

\section{PENELITIAN RELEVAN}

Penelitian yang berhubungan dengan perancangan aplikasi persediaan barang sudah pernah dilakukan oleh beberapa peneliti diantaranya penelitian yang dilakukan (Assyadan, 2020) dengan judul Rancang Bangun Aplikasi Inventory Alat Tulis Kerja Pada SMK Purna Usaha Tama. Pada Inventory ATK di Sekolah Purna Usaha Tama pada bagian TU segala kegiatan keluar - masuknya barang masih manual dalam pencatatan serta rekapitulasi dengan buku arsip. Selama ini inventory ATK di sekolah belum mempunyai aplikasi khusus untuk inventaris barang sehingga belum semuanya terkomputerisasi. Bagaimana membuat aplikasi yang tepat, cepat serta akurat sebagai inventory alat tulis kerja agar dapat membantu staf tata usaha dan sekolah dengan efektif juga efisien. Penelitian tersebut menggunakan tema SMBD dan metode kuantitatif untuk mengolah data berupa penghitungan stok barang serta keluar - masuk barang yang menggunakan single user untuk admin pada staf tata usaha. Dengan hadirnya aplikasi inventory barang, monitoring dan manjemen kegiatan barang di gudang akan tersimpan rapi, aman serta akurat pada database yang sistematis. Meningkatkan kinerja karyawan demi menyeimbangkan kemajauan teknologi industri 4.0 pada segi manajemen maupun monitoring, kegiatan inventory barang membentuk sistem yang dapat lebih maju dari sebelumnya.

Penelitian yang dilakukan oleh (Wijoyo\&Hermanto, 2020) dengan judul Analisis dan Perancangan Sistem Informasi Inventory Pada PT. Insan Data Permata. Sistem inventory adalah suatu sistem yang berfungsi mengetahui kapasitas stok barang disuatu tempat. Sistem inventory banyak digunakan dan dikembangkan di suatu tempat dengan bermacam teknologi dan juga sistem. Permasalahan di PT.Insan Data Permata yaitu belum tersedianya sistem persediaan barang sehingga belum dapat mengontrol persediaan barang yang tersedia. Maka peneliti akan membangun sebuah sistem inventory berbasis desktop, agar informasi tentang persediaan barang dapat diketahui secara jelas serta terperinci. Sistem inventory tersebut akan diterapkan dengan sistem informasi yang berbasis desktop. Program tersebut dibuat dengan menggunakan software XAMPP dan netbeans 8.2 serta database MYSQL. Dalam penelitian tersebut dilakukan pendekatan dengan analisis kualitatif. Analisis kualitatif merupakan suatu penggambaran data yang menggunakan pendekatan kualitatif serta bertujuan memahami situasi pada karyawan yang meliputi peran, interaksi dan kelompok. Program ini berfungsi sebgao pengolah data tentang implementasi suatu sistem informasi persediaan di PT. Insan Data Permata. Dengan adanya aplikasi informasi inventory di PT. Insan Data Permata, kegiatan yang memiliki hubungan dengan pendaftaran pelanggan, pengolahan transaksi, pengolahan barang, penjualan barang serta laporan tidak lagi manual.

\section{METODE PENELITIAN}

Metode penelitian yang peneliti lakukan adalah metode penelitian dengan tahapan sebagai berikut :

1. Metode Penelitian

Metode penelitian yang dipakai oleh peneliti dalam tugas akhir ini adalah metode grounded research.

2. Metode Pengumpulan Data

Metode pengumpulan data dilakukan oleh peneliti agar mendapatkan data serta informasi guna mendukung penyempurnaan dari penelitian ini yaitu :

a. Observasi

Peneliti mempelajari dan mengamati data - data yang terdapat di CV Ridho Karya Mandiri sebagai sumber informasi untuk mengumpulkan data yang diperlukan. Data - data yang diamati dan dipelajari peneliti antara lain yaitu data stok barang, data pelanggan, data supplier, data barang masuk serta data barang keluar yang dimiliki oleh CV Ridho Karya Mandiri.

b. Wawancara 
Peneliti melakukan wawancara kepada Bapak Carwid Syah Bhenny sebagai manajer operasional, Bapak Iwan sebagai quality control dan Bapak Nian yang bertugas pada bagian gudang untuk mendapatkan data dan informasi yang dibutuhkan.

3. Langkah - Langkah Pengembangan Sistem

Dalam pengembangan aplikasi persediaan barang yang menggunakan java netbeans peneliti menggunakan pemodelan waterfall (air terjun). Berikut adalah tahapannya :

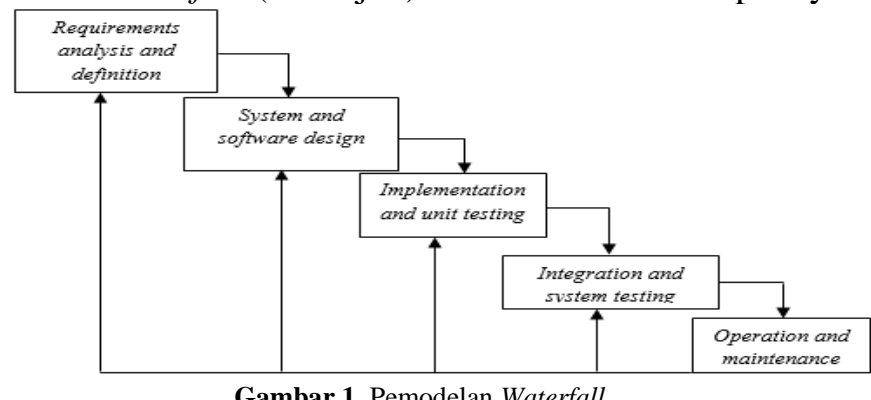

a. Requirements Analysis dan Definition

Mengumpulkan kebutuhan dengan lengkap kemudian dianalisis lalu didefinisikan kebutuhan yang perlu dipenuhi dengan program yang akan dibuat. Fase ini wajib dikerjakan secara lengkap agar dapat menghasilkan desain yang sempurna.

b. System dan Software Design

Desain dilakukan setelah apa yang dibutuhan selesai dikumpulkan dengan lengkap.

c. Implementation dan Unit Testing

Desain aplikasi diterjemahkan dalam kode - kode memakai bahasa pemrograman yang telah ditentukan. Program yang dibuat langsung diuji secara unit.

d. Integration dan System Testing

Penyatuan bagian program lalu diuji secaramenyeluruh (system testing).

e. Operation dan Maintenance

Mengoperasikan program dibagiannya dan melakukan pemeliharaan berupa penyesuaian atau perubahan yang disebabkan karena adaptasi pada situasi sebenarnya.

\section{HASIL DAN PEMBAHASAN}

\section{Analisis Permasalahan}

Permasalahan - permasalahan dari sistem persediaan barang yang sedang berjalan yaitu :

a. Tidak tersedianya sistem pengolahan data persediaan barang yang terkomputerisasi.

b. Pimpinan (manajer) sering merasa kesulitan pada saat memerlukan informasi tentang persediaan barang karena harus mengecek secara langsung ke bagian gudang.

c. Sistem yang berjalan saat ini yang masih menggunakan pencatatan keluar masuk barang secara manual dalam buku besar sehingga kurang efektif dalam pembuatan laporan.

d. Kurangnya keakuratan, efisiensi dan kerangkapan data dalam pengadaan barang yang disebabkan proses manual.

e. Adanya tuntutan waktu yang mendesak, seiring dengan besarnya volume transaksi yang harus dipenuhi. Dikarenakan sistem yang digunakan bersifat manual, maka kecepatan dalam pengolahan data masih jauh dari yang dikehendaki manajer.

\section{Alternatif Penyelesaian Masalah}

Melihat kasus yang terjadi diatas, peneliti mencoba memberikan solusi untuk mengatasi permasalahan tersebut, antara lain :

a. Membuat media penyampaian informasi yang terkomputerisasi agar dapat memberikan informasi kepada manajer tentang laporan hasil transaksi barang masuk serta barang keluar maupun data stok barang, data supplier dan data pelanggan.

b. Membuat aplikasi persediaan barang yang merupakan paradigma baru, dimana pengguna dapat memasukan data - data kedalam sistem dengan cepat dan akurat.

c. Perlu adanya pemberitahuan dan pengetahuan akan pentingnya dokumentasi yang sesuai khususnya untuk segala bentuk transaksi persediaan barang. 
d. Menggunakan bahasa pemrograman java dalam pembuatan aplikasi persediaan barang.

\section{Aturan Bisnis Sistem yang Diusulkan}

Use Case Diagram Sistem yang Diusulkan

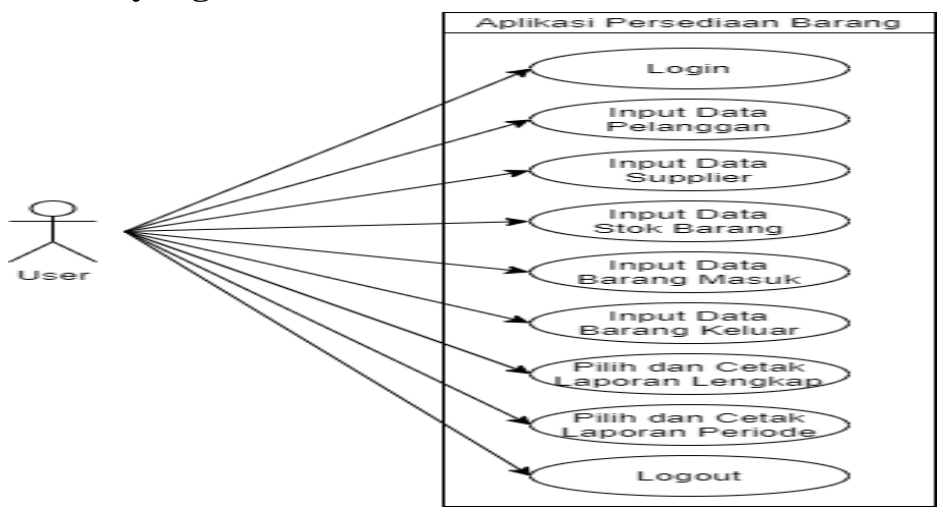

Gambar 2. Use Case Diagram Sistem yang Diusulkan

\section{Activity Diagram Sistem yang Diusulkan Barang Keluar}

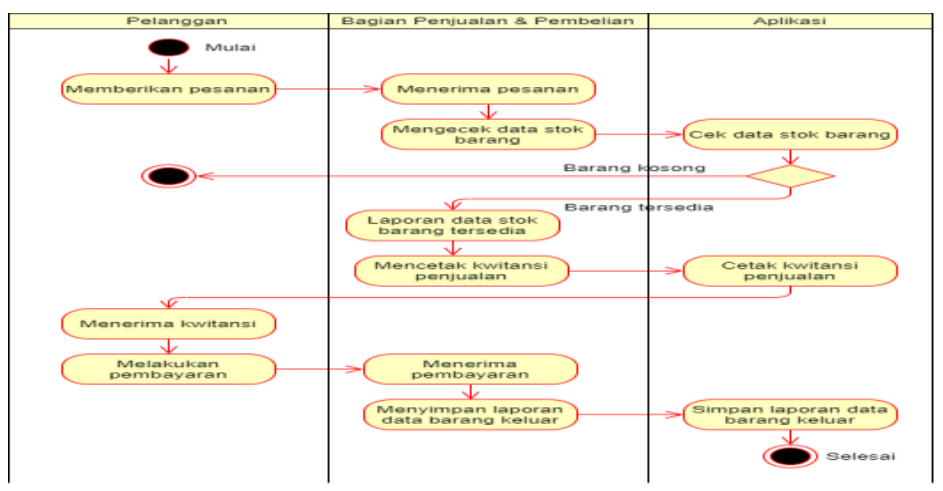

Gambar 3. Activity Diagram Sistem yang Diusulkan Barang Keluar

\section{Activity Diagram Sistem yang Diusulkan Barang Masuk}

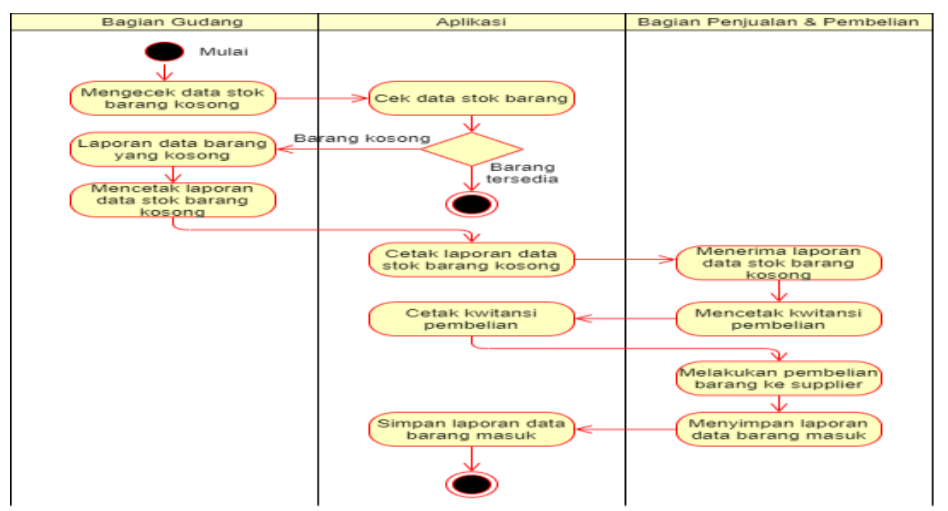

Gambar 4. Activity Diagram Sistem yang Diusulkan Barang Masuk

\section{Class Diagram Sistem yang Diusulkan}




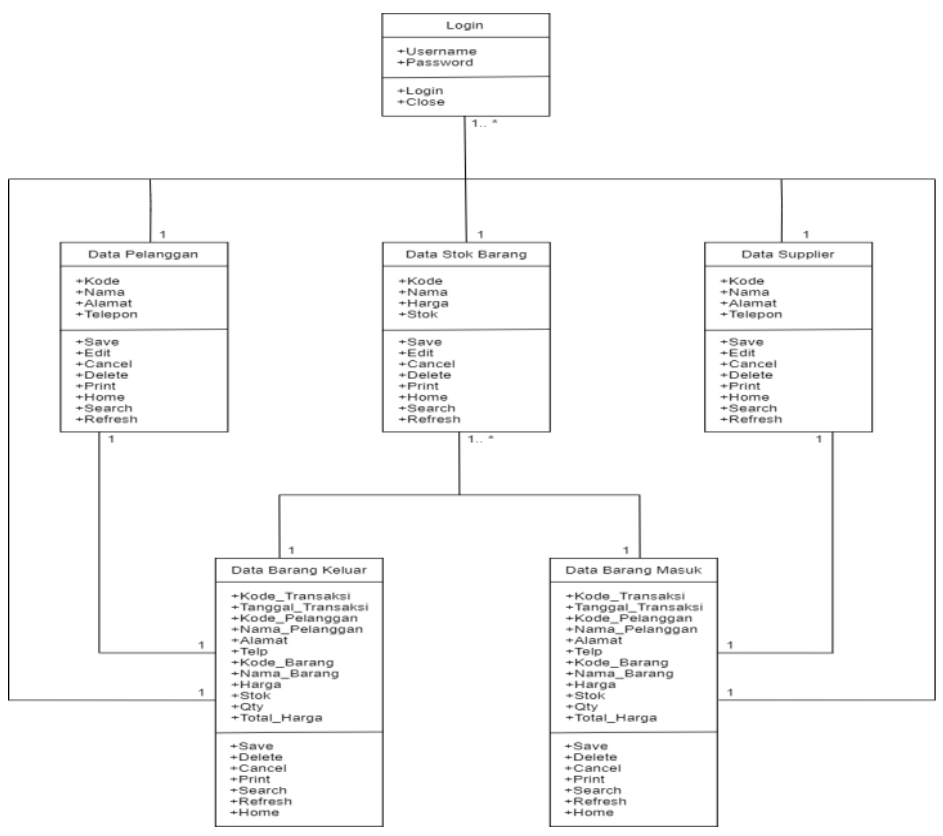

Gambar 5. Class Diagram Sistem yang Diusulkan

\section{Tampilan Layar}

Tampilan layar (user interface) digunakan untuk menunjukkan desain akhir antar muka aplikasi terhadap pengguna dengan aplikasi dalam bentuk tampilan gambar.

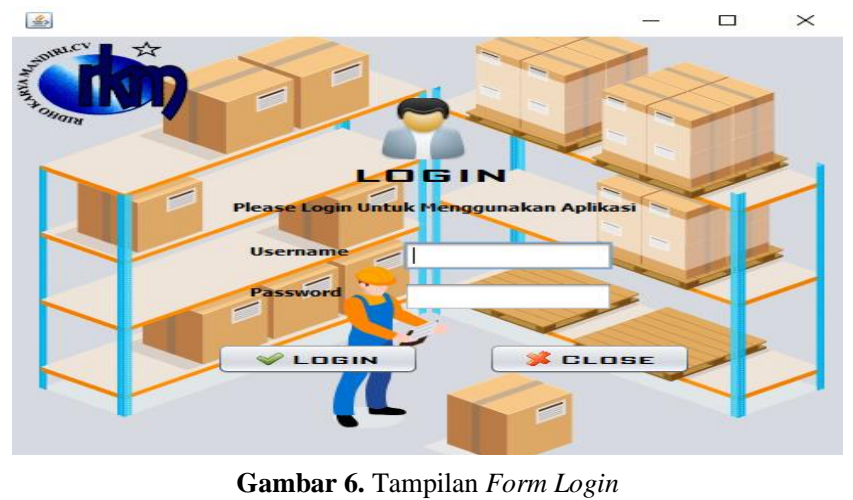

Tampilan form login berfungsi sebagai pembatas hak akses pada perangkat lunak ini. Pengguna harus memasukan username serta password untuk masuk pada halaman selanjutnya.

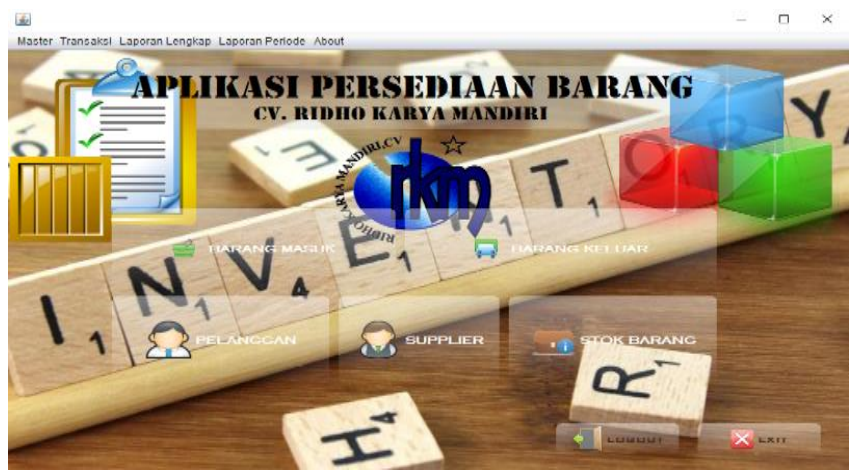

Gambar 7. Tampilan Form Menu Utama

Tampilan form menu utama aplikasi persediaan barang merupakan tampilan awal setelah login yang berisi menu master, menu transaksi, menu laporan lengkap, menu laporan periode dan menu about. 


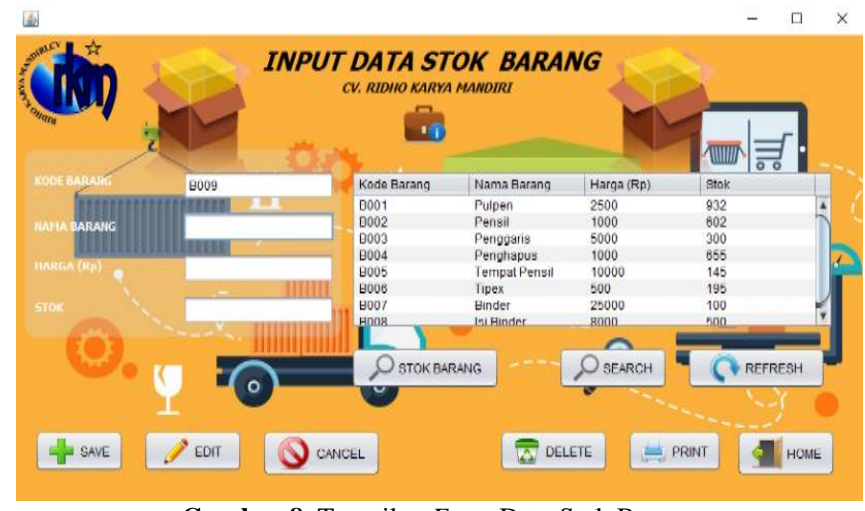

Gambar 8. Tampilan Form Data Stok Barang

Tampilan form data stok barang berfungsi untuk memasukan dan menyimpan data stok barang, meng-edit data stok barang, menghapus data stok barang, mencari data stok barang dan mencetak data stok barang.

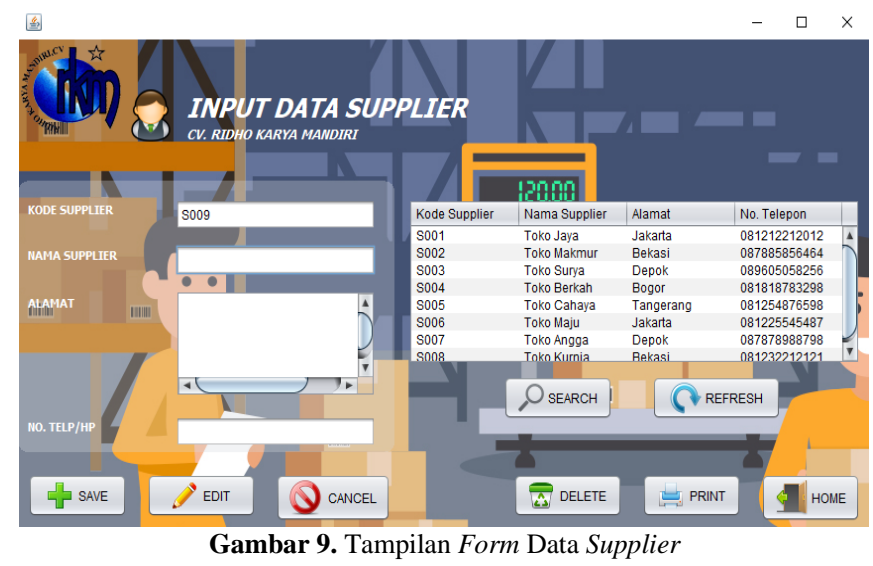

Tampilan form data supplier berfungsi untuk memasukan dan menyimpan data supplier, meng-edit data supplier, menghapus data supplier, mencari data supplier dan mencetak data supplier.

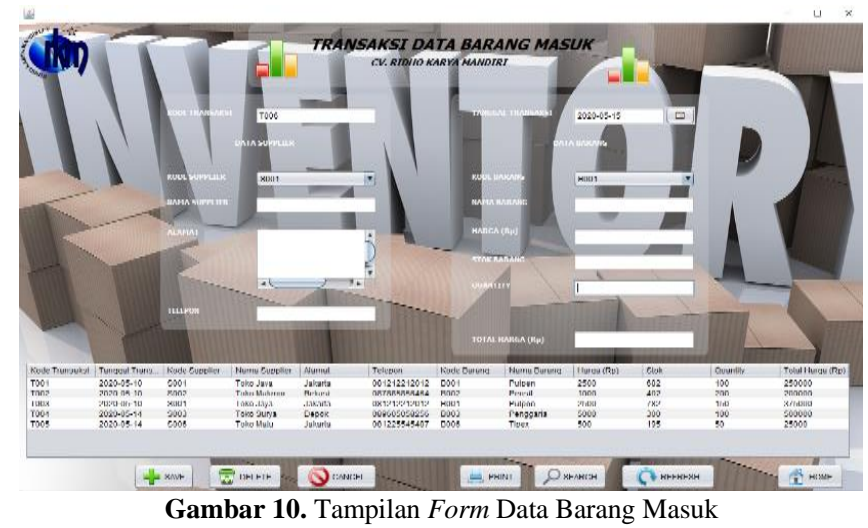

Tampilan form data barang masuk berfungsi untuk memasukan kode dan tanggal transaksi, memasukan data - data supplier, memasukan data - data barang, menyimpan data transaksi barang masuk, menghapus data transaksi barang masuk, mencari data transaksi barang masuk dan mencetak data transaksi barang masuk. 


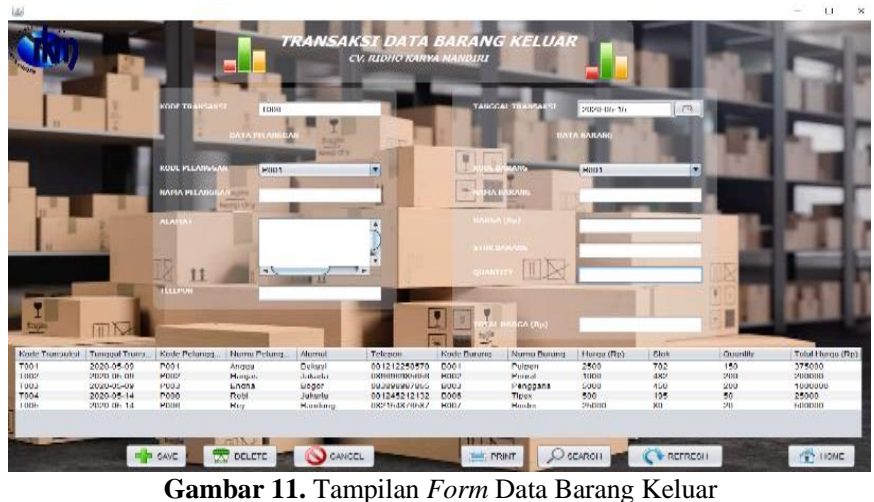

Tampilan form data barang keluar berfungsi untuk memasukan kode dan tanggal transaksi, memasukan data - data pelanggan, memasukan data - data barang, menyimpan data transaksi barang keluar, menghapus data transaksi barang keluar, mencari data transaksi barang keluar dan mencetak data transaksi barang keluar.

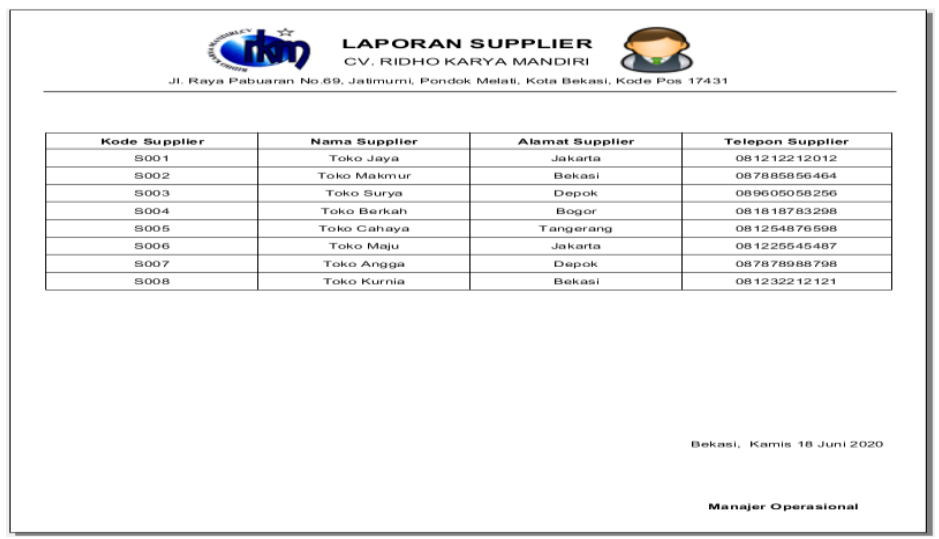

Gambar 12. Tampilan Laporan Data Supplier

Tampilan laporan data supplier berisi tentang data kode supplier, nama supplier, alamat supplier dan telepon supplier.

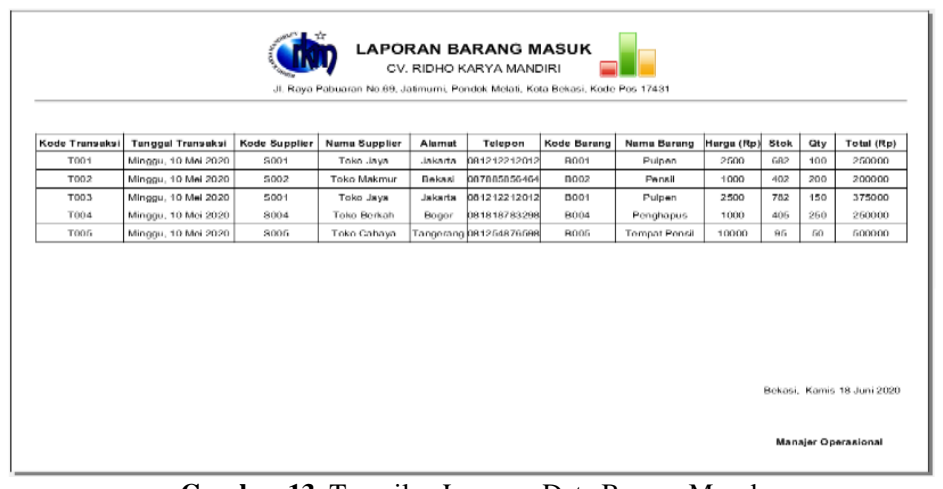

Gambar 13. Tampilan Laporan Data Barang Masuk

Tampilan laporan data barang masuk berisi tentang kode transaksi, tanggal transaksi, kode supplier, nama supplier, alamat supplier, telepon supplier, kode barang, nama barang, harga, stok, qty dan total harga. 


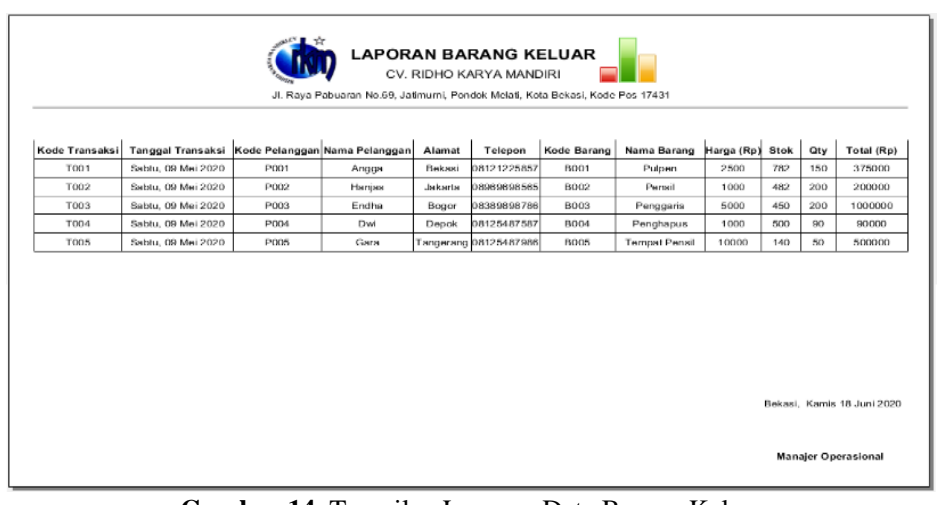

Gambar 14. Tampilan Laporan Data Barang Keluar

Tampilan laporan data barang keluar berisi tentang kode transaksi, tanggal transaksi, kode pelanggan, nama pelanggan, alamat pelanggan, telepon pelanggan, kode barang, nama barang, harga, stok, qty dan total harga.

\section{SIMPULAN}

Dengan dibangunnya aplikasi ini, maka proses dalam kegiatan pengelolaan persediaan barang pada CV Ridho Karya Mandiri menjadi terkomputerisasi serta lebih efektif serta efisien sehingga memudahkan bagian gudang dalam setiap pengelolaan data dan juga mengurangi kesalahan dalam mengolah data serta penyimpanan data yang lebih terjamin karena tersimpan pada database.

\section{DAFTAR PUSTAKA}

Asropudin, P. (2013). Kamus Teknologi Informasi. Bandung: Titian Ilmu.

Assyadan, E. (2020). Rancang Bangun Aplikasi Inventory Alat Tulis Kerja pada SMK Purna Usaha Tama. Jurnal Riset Dan Aplikasi Mahasiswa Informatika (JRAMI), 1(01), 45-51. https://doi.org/10.30998/jrami.v1i01.172

Buana, I. K. S. (2014). Jago Pemrograman PHP. Jakarta: Dunia Komputer.

Nofriadi. (2015). Java Fundamental dengan Netbeans 8.0.2. Yogyakarta: DeePublish.

Sartono, A. (2010). Manajemen Keuangan Teori dan Aplikasi. Edisi Keempat. Yogyakarta: BPFE.

Shalahuddin, M., \& Rosa, A. S. (2013). Rekayasa Perangkat Lunak Terstruktur dan Berorientasi Objek. Bandung: Informatika.

Sutanta, E. (2011). Basis Data dalam Tinjauan Konseptual. Yoyakarta: CV Andi Offset.

Wijoyo, A. C., \& Hermanto, D. (2020). Analisis dan Perancangan Sistem Informasi Inventory pada PT Insan Data Permata. Jurnal Riset Dan Aplikasi Mahasiswa Informatika (JRAMI), 1(02), $165-170$. https://doi.org/10.30998/jrami.v1i02.231 